\title{
EVALUATION ON ECG TRAINING PROGRAM FOR INTERNS AND POSTGRADUATES
}

\author{
Suresh $K^{1}$, Badrinath A. K², Suresh Babu³, Mridula Eswarawaha ${ }^{4}$
}

${ }_{1}^{1}$ Associate Professor, Department of Internal Medicine, Manakula Vinayagar Medical College, Pudhucherry.

2Professor, Department of Internal Medicine, Manakula Vinayagar Medical College, Pudhucherry.

${ }^{3}$ Resident, Department of Internal Medicine, Manakula Vinayagar Medical College, Pudhucherry.

${ }^{4}$ Resident, Department of Internal Medicine, Manakula Vinayagar Medical College, Pudhucherry.

ABSTRACT
BACKGROUND
The electrocardiography is a basic and commonly used diagnostic test, which is really expected to know by the resident doctors
and also by interns. There is no structured teaching methods for this. So, we intended to evaluate the ability of residents to
interpret ECG.

\section{MATERIALS AND METHODS}

A hospital-based uncontrolled educational interventional study done includes 22 interns and 11 PG residents with total of 33 students from Sri Manakula Vinayagar Medical College, Pudhucherry, were enrolled in our study. A pre-test consisting of 33 ECG samples were associated with a questionnaire. This study was conducted under the supervision of a cardiologist and internal medicine specialist who supervised the ECG selection, answers and scoring of each ECG.

\section{RESULTS}

There were 33 participants included in the study, among them majority (66.7\%) were interns and remaining were PGs (33.3\%) and most of their pre-test knowledge was from self-study (51.5\%). In this study, $66.9 \%$ of them told this training was useful and $30 \%$ told very useful. According to paired ' $\mathrm{t}$ ' test when compared pre- and post-test assessment, there was significant improvement from $22 \%$ to $60 \%$ ( $p>0.05$ ) in reading the ECG and diagnose the emergency conditions.

\section{CONCLUSION}

According to this study, the educational programs on electrocardiography may improve resident's correct diagnostic rate and also may be able to identify treating in the emergency conditions. Focused educational programs in the problem areas may further reduce the error rate in diagnosing such conditions.

\section{KEYWORDS}

ECG Interpretation, Residents, Emergency Conditions, Cardiac Diseases, Dysrhythmias.

HOW TO CITE THIS ARTICLE: Suresh K, Badrinath AK, Babu S, et al. Evaluation on ECG training program for interns and postgraduates. J. Evolution Med. Dent. Sci. 2018;7(04):407-410, DOI: 10.14260/jemds/2018/91

\section{BACKGROUND}

The electrocardiogram (ECG) is a basic and commonly used diagnostic test in heart diseases. Most medical professionals are expected to possess basic ECG interpretation skills and as such it has become part of the curriculum for medical students undergoing their internal medicine rotations and training.[1]

ECG abnormalities can reveal the early manifestations of cardiac ischaemia, metabolic disorders or life-threatening dysrhythmias. Misinterpretation of ECG and its consequent mistreatment or performing inessential interventions may cause life-threatening cardiac events.(2) So electrocardiography is considered an important method in the diagnosis of cardiac diseases and therefore ECG training is considered an essential course in the medical education curriculum. (3)

'Financial or Other Competing Interest': None.

Submission 30-12-2017, Peer Review 12-01-2018,

Acceptance 15-01-2018, Published 22-01-2018.

Corresponding Author:

Dr. Suresh $K$

Associate Professor,

Department of Internal Medicine,

Sri Manakula Vinayagar Medical College.

Madagadipet, Pudhucherry 605107

E-mail: sureshsuchu@yahoo.co.in

DOI: $10.14260 /$ jemds $/ 2018 / 91$
Since interns and Internal Medicine (IM) residents are usually the first to visit at bedside and start treatments based on patient's ECG, their knowledge in interpreting electrocardiographs were supposed to be adequate. But there are few studies aimed to assess the ability of interns and medicine residents in ECG interpretation. $(4,5)$

However, factors contributing to successful achievement of correct interpretation of ECG are mostly unknown. So we intended to evaluate the ability of residents to interpret ECG.

\section{Objectives}

To evaluate the ECG training program by testing of students.

\section{MATERIALS AND METHODS}

A hospital-based uncontrolled educational interventional study done, which includes 22 interns and 11 PG residents with total of 33 students from Sri Manakula Vinayagar Medical College, Madagadipet, Pudhucherry, who was posted in Department of Internal Medicine were enrolled in our study. In Medicine Department demonstration hall all are asked to assemble between 12 noon - 1 pm. The following sessions were conducted-

1. How to read an ECG?

2. Bradyarrhythmias.

3. Tachyarrhythmias.

4. Coronary emergencies.

5. Non-coronary emergencies. 
Before each session starts, pre-test was conducted with questionnaire that contains a total of 33 types of ECG collections, which was taken by the assistant and associate professors of the Internal Medicine Department, also with supervision of the consultant cardiologist of the institution and the answer paper was collected immediately. The following type of teaching methods were used for each session-

1. Small power point presentation with subtopics (e.g. CAD, Bradyarrhythmias)- 15 minutes daily for 1 week.

2. Bedside ECG discussion during ward rounds.

3. Discussion with interesting ECG collections.

Then post-test was conducted with the same questionnaire that contains 33 types of ECG collections asked in the pre-test. With key answers prepared, papers were corrected. Once the test was over after the paper correction marks were entered in the data sheet, data were given to the statistician to do statistical analysis. Pre- and post-test results were analysed by paired ' $t$ ' test.

\section{RESULTS}

Assessment of ECG knowledge of CRRIs and PGs:

\begin{tabular}{|c|c|c|}
\hline Please Specify your Designation & Frequency & $\%$ \\
\hline CRRI & 22 & $66.7 \%$ \\
\hline First Year PG & 4 & $12.1 \%$ \\
\hline Second Year PG & 3 & $9.1 \%$ \\
\hline Third Year PG & 4 & $12.1 \%$ \\
\hline Total & 33 & $100.0 \%$ \\
\hline \multicolumn{3}{|c|}{ Table 1. Designation of the Participants } \\
\hline
\end{tabular}

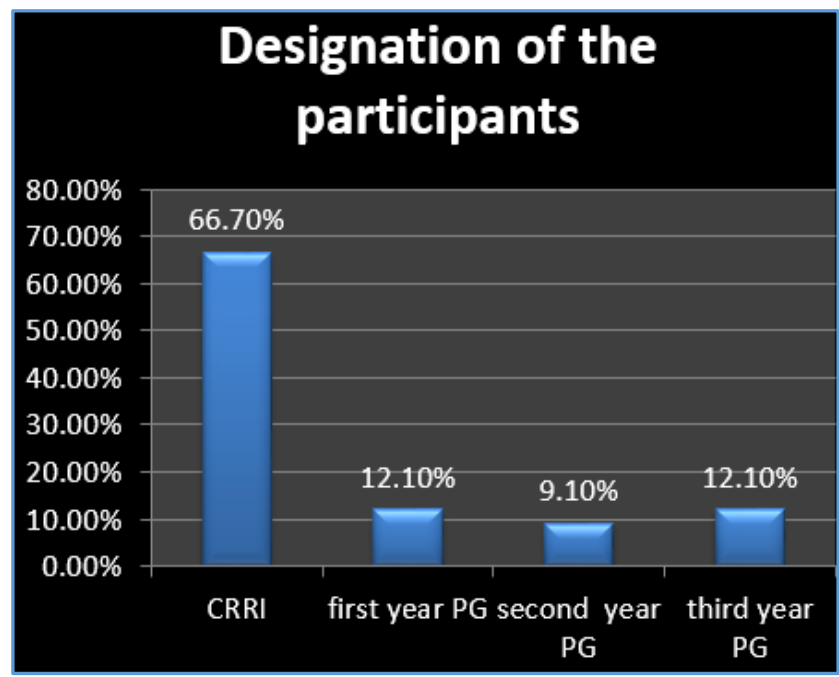

Figure 1. Designation of the Participants

Among 33 participants including 22 CRRIs (66.7\%) and 11 PG (33.3\%) residents, which includes 2 from every academic year from Department of Internal Medicine from Sri Manakula Vinayagar Medical College, Pudhucherry, were enrolled in our study. They were requested to come after finishing their ward work. A diagnosis test consisting of 33 ECG samples associated with a questionnaire containing questions about gender, academic year and proficiency in ECG interpretation was taken from all participants. This study was conducted under the supervision of a cardiologist and internal medicine specialist who supervised the ECG selection, answers and scoring of each ECG. All were given the same questionnaire (Table 1 and Figure 1).

\begin{tabular}{|c|c|c|}
\hline $\begin{array}{c}\text { Previous Specific ECG Training: } \\
\text { In which Format did you receive } \\
\text { your previous ECG Teaching }\end{array}$ & Frequency & $\mathbf{\%}$ \\
\hline Medical School & 6 & $18.2 \%$ \\
\hline ECG Workshops & 7 & $21.2 \%$ \\
\hline Formalised ECG Teaching & 2 & $6.1 \%$ \\
\hline Internet Based Teaching & 1 & $3.0 \%$ \\
\hline Self-Study & 17 & $51.5 \%$ \\
\hline Total & $\mathbf{3 3}$ & $\mathbf{1 0 0 . 0 \%}$ \\
\hline \multicolumn{2}{|c|}{ Table 2. Previous ECG Training } \\
\hline
\end{tabular}

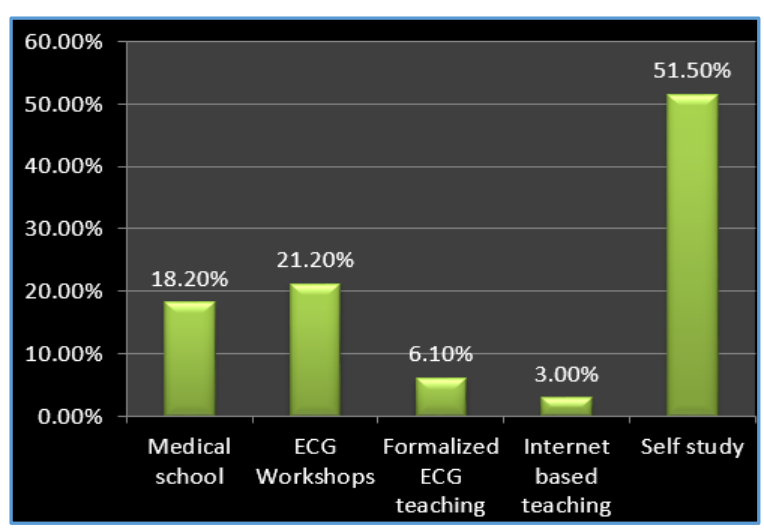

Figure 2. Previous ECG Training

It has been observed that majority of them learned ECG by self $(51.5 \%)$ through books during their initial part of internship, during their clinical medicine posting and routine ward rounds and errands. Few of them underwent workshop and had attended definite structured training course during their student life. Also, few of them had taken self-learning course over the Internet without any proper appraisal. To summarise, there was no structured form of ECG teaching module to train them in definite diagnosis during undergraduate or postgraduate levels (Table 2 and Figure 2), in spite of ECG interpretation being part of core competency skill of the Medical curriculum.

\begin{tabular}{|c|c|c|}
\hline Introduction to ECG & Frequency & Percentage \\
\hline Yes & 22 & $66.7 \%$ \\
\hline No & 11 & $33.3 \%$ \\
\hline Total & 33 & $100.0 \%$ \\
\hline \multicolumn{3}{|c|}{ How to Read an ECG } \\
\hline Yes & 20 & $60.6 \%$ \\
\hline No & 13 & $39.4 \%$ \\
\hline Total & 33 & $100.0 \%$ \\
\hline \multicolumn{3}{|c|}{ Tachyarrhythmias } \\
\hline Yes & 20 & $60.6 \%$ \\
\hline No & 13 & $39.4 \%$ \\
\hline Total & 33 & $100.0 \%$ \\
\hline \multicolumn{3}{|c|}{ Bradyarrhythmias } \\
\hline Yes & 16 & $48.5 \%$ \\
\hline No & 17 & $51.5 \%$ \\
\hline Total & 33 & $100.0 \%$ \\
\hline \multicolumn{3}{|c|}{ Acute Coronary Syndrome } \\
\hline Yes & 20 & $60.6 \%$ \\
\hline No & 13 & $39.4 \%$ \\
\hline Total & 33 & $100.0 \%$ \\
\hline \multicolumn{3}{|c|}{ Non-Coronary Emergencies } \\
\hline Yes & 19 & $57.6 \%$ \\
\hline No & 14 & $42.4 \%$ \\
\hline Total & 33 & $100.0 \%$ \\
\hline
\end{tabular}


It has been observed overall that on an average there was $60 \%$ attendance in almost all sessions, except for the session of Bradyarrhythmias where it was less (48.5\%), most probably due to the weekend session.

\begin{tabular}{|c|c|c|c|c|c|c|c|c|c|}
\hline \multirow[t]{3}{*}{ Paired Samples Test } & \multirow{3}{*}{ Mean } & & \multicolumn{4}{|c|}{ Paired Differences } & \multirow[t]{3}{*}{$\mathbf{t}$} & \multirow[t]{3}{*}{ df } & \multirow[t]{3}{*}{ Sig. (2-Tailed) } \\
\hline & & $\mathrm{N}$ & $\begin{array}{c}\text { Std. } \\
\text { Deviation }\end{array}$ & $\begin{array}{l}\text { Std. Error } \\
\text { Mean }\end{array}$ & \multicolumn{2}{|c|}{$\begin{array}{c}\text { 95\% Confidence } \\
\text { Interval } \\
\text { of the Difference }\end{array}$} & & & \\
\hline & & & & & Lower & Upper & & & \\
\hline $\begin{array}{l}\text { Pre-Test } \\
\text { Post-Test }\end{array}$ & $\begin{array}{c}5.1290 \\
14.2258\end{array}$ & $\begin{array}{l}31 \\
31\end{array}$ & $\begin{array}{l}3.30648 \\
5.22947\end{array}$ & $\begin{array}{l}.59386 \\
.93924\end{array}$ & & & & & \\
\hline \multicolumn{10}{|l|}{ Paired Samples Statistics } \\
\hline Pre-Test and Post-Test & -9.0968 & & 3.06980 & .55135 & -10.2228 & -7.9708 & -16.499 & 30 & .0001 \\
\hline Paired Samples Correlation & & & \multicolumn{6}{|c|}{ Correlation } & \\
\hline \begin{tabular}{|l|} 
Pair 1 Pre-Test and Post-Test \\
\end{tabular} & 31 & & \multicolumn{6}{|c|}{.834} & .0001 \\
\hline
\end{tabular}

p- value $<0.05$ statistically significant.

When comparing pre- and post-test evaluation, the mean pre-test mark is 5.1 and mean post-test is 14.2 . It is very significant improvement in performance of the students after the ECG training, which implies that CRRI and PGs need special training (Table 4). When we evaluated the pre-test, there was only $22.2 \%$ marks scored by overall irrespective of the designations. There was no difference in scoring between the interns and the PGs, and also there was no difference in scoring between the PGs. Definitely, they need a structured programme to improve their knowledge in interpreting the ECG. In post-test evaluation $60 \%$ of the students were able to interpret the rhythm abnormalities and coronary artery abnormalities, which was recognised with ease. They felt difficulty in rhythm disorders, especially like bradyarrhythmias which was only 48\%. ECG of non-coronary emergencies was 58\%, which really increased their enthusiasm in learning the ECGs.

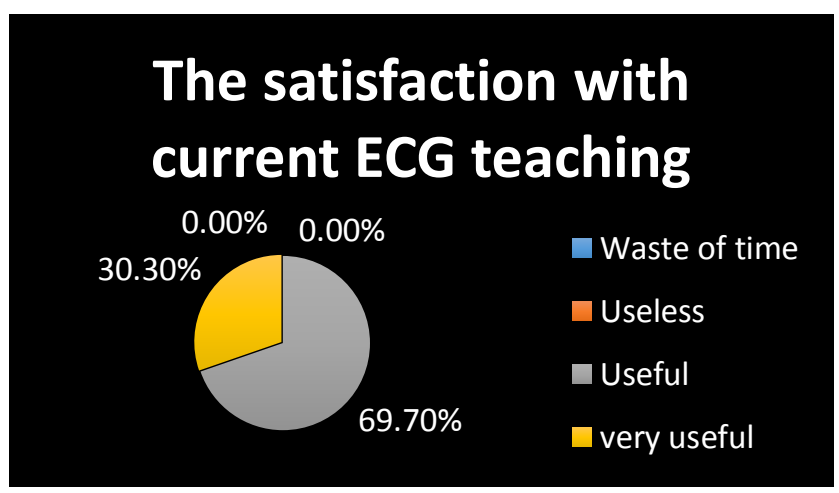

Figure 3. The Satisfaction with Current ECG Teaching

When we assessed the feedback, we found that $69.7 \%$ students found that this teaching was useful and $30.3 \%$ found it very useful as per Figure 3. Nobody told that the classes were useless and waste of time. In fact, they suggested that this kind of programme should be conducted regularly. In a study conducted by Jack Rubinstein et al, a total of 15 students participated in the course. All considered EKG interpretation to be an important $(30 \%)$ or very important (70\%) skill to have.(6)

\begin{tabular}{|c|c|c|}
\hline $\begin{array}{c}\text { What are the Problems of } \\
\text { Attending Classes? }\end{array}$ & Frequency & Percentage \\
\hline Night Duty & 7 & $22.6 \%$ \\
\hline Tiredness & 4 & $12.9 \%$ \\
\hline Illness & 2 & $6.5 \%$ \\
\hline Ward Work & 17 & $54.8 \%$ \\
\hline Fear of Test & 1 & $3.2 \%$ \\
\hline Total & $\mathbf{3 1}$ & $\mathbf{1 0 0 . 0} \%$ \\
\hline Table 5. Common Problems in Attendance \\
\hline
\end{tabular}

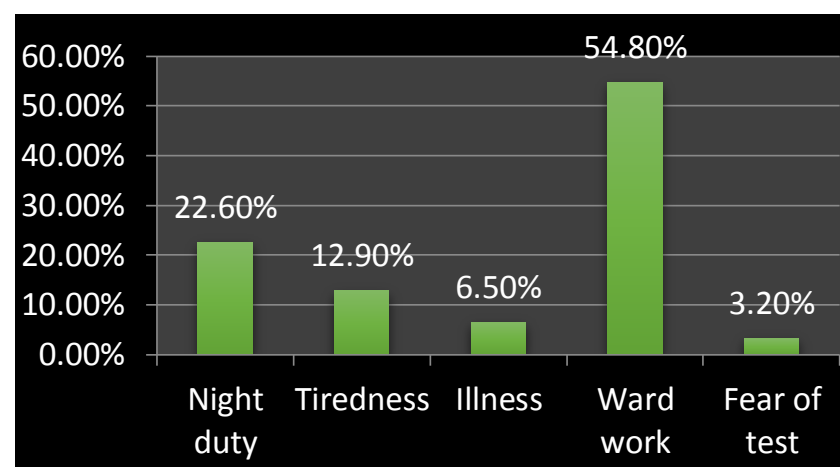

Figure 4. Common Problems in Attendance

When we analysed the reason for absence it was found to be mostly due to ward work (54.8\%), night duty (22.6\%), fatigue $(12.9 \%)$ and very few $(10 \%)$ had illness and fear of test. Overall, the feedback given positively by the students was $80 \%-82 \%$ and many of them found it was very useful and suggested many more sessions and ECG teaching rounds and mini tests. If there is a structured programme, work time can be adjusted according to the programme.

\section{DISCUSSION}

Many studies similar to our study like Karimpoor Tari et al selected 30 emergency ward residents; 16 from first year and 14 at the end of second year since the residents as prime target of the study population similar to our study, since they are the one who first deal with the patient.(7) As in Figure 1 study of SA Mahler et al compared with those taught in workshop and lecture-based formats, medical students learning ECG interpretation by self-directed learning had lower test scores, as it is the same in our studies. Most had some self-reported EKG exposure prior to the course with $11 / 13$ (84\%) using books and 5/13 (39\%) during clinical rounds. $(8)$ 
Similar to our study as in Figure 2 B Little et al, the 12lead ECG tracings were correctly assigned in 54\%. The inferior myocardial infarct was the most recognised with 28 (61\%) of the group detecting it. Atrial fibrillation was correctly diagnosed by $25(54 \%)$ and the normal ECG was categorised as such by 21 (46\%) of the group.(4) The highest level of certainty was found when interpreting ECGs representing AMI (55\%) and atrial flutter $(60 \%)$ similar to our study as in Table 1, Japie De Jager et al.(6) In this study, we found the overall average of ECG interpretation was $46.4 \%$ [95\% confidence interval (CI) 41.5 - 51.2\%]. The junior group had an overall average of $42.2 \%$ (95\% CI 36.9 - 47.5\%), while the senior group managed $52.5 \%$ (95\% CI 43.4 - 61.5\%). There was an improvement in ECG interpretation between the junior and senior groups in this study ( $\mathrm{p}=0.035$, $\mathrm{t}$-test).(6) Our study is similar to Eslava et al. The study sample consisted of 52 PGY-1 residents at a large university hospital in New York City. The participants were within their first 2 weeks of starting their IM training. There were no significant differences in the scores achieved by preliminary PGY-1 and categorical PGY-1 (9.6 \pm 3.4 vs. $9.7 \pm 4.1$, respectively). The subgroup that had previously received formal ECG instruction had correct rhythm-strip identification in $93 \%$ of cases and correct 12-lead ECG interpretation in 64\% of cases,(1) B Little et al. The subgroup without previous formal instruction had lower rates of $83 \%$ and $43 \%$ respectively. The difference in correct interpretation rates was significant (T-Test, unpaired sample, unequal variance) for both rhythmstrips and for 12-lead ECG tracings ( $p<0.05)$. This suggests that previous formal teaching on the interpretation of ECG tracings produced a statistically significant improvement in ability.

As mentioned in study of Japie De Jager, the quality of ECG interpretation by individuals could be affected by other factors like tiredness, night duty and illness which was found to be the limitations of the performance of the residents in our study.(6) Another important issue as coated in the study of Karimpoor Tari HR et al is that there is no predefined schedule for classic ECG training in the curriculum for emergency residents and their education is mostly performed by attending on patient's bedside.(7) When they gave feedback, most of them found this kind of classes were very useful. As mentioned in the study of Japie De Jager et al,(6) the majority of residents requested more formal ECG teachings, bedside ECG teaching and ECG workshops during the training programme.

\section{CONCLUSION}

There were 33 participants included in the study. Among them majority $(66.7 \%)$ were interns and remaining were PGs
(33.3\%), and most of their pre-test knowledge was from selfstudy (51.5\%). In this study, $66.9 \%$ of them told this training was useful and $30 \%$ told very useful. According to paired ' $\mathrm{t}$ ' test when compared pre- and post-test assessment, there was significant improvement $(\mathrm{p}>0.05)$ in reading the ECG and diagnose the emergency conditions. All of them found this training programme were very useful and need frequent classes in future and suggested for the formal ECG teaching.

Overall, the study stresses the need of educational programs on electrocardiography which may improve resident's correct diagnostic rate and also may identify clinicians with diagnostic difficulties. So focused educational programs in the problem areas may further reduce the error rate.

\section{REFERENCES}

[1] Eslava D, Dhillon S, Berger J, et al. Interpretation of electrocardiograms by first-year residents: the need for change. J Electrocardiol 2009;42(6):693-7.

[2] Kadish AH, Buxton AE, Kennedy HL, et al. ACC/AHA clinical competence statement on electrocardiography and ambulatory electrocardiography: a report of the ACC/AHA/ACP-ASIM task force on clinical competence (ACC/AHA committee to develop a clinical competence statement on electrocardiography and ambulatory electrocardiography) endorsed by the International Society for Holter and noninvasive electrocardiology. Circulation 2001;104(25):3169-78.

[3] Fisch C. Evolution of the clinical electrocardiogram. J Am Coll Cardiol 1989;14(5):1127-38.

[4] Little B, Mainie I, Ho KJ, et al. Electrocardiogram and rhythm strip interpretation by final year medical students. Ulster Med J 2001;70(2):108-10.

[5] Berger JS, Eisen L, Nozad V, et al. Competency in electrocardiogram interpretation among internal medicine and emergency medicine residents. Am J Med 2005;118(8):873-80.

[6] de Jager J, Wallis L, Maritz D. ECG interpretation skills of South African emergency medicine residents. Int J Emerg Med 2010;3(4):309-14.

[7] Tari HRK, Dolatabadi AA, Miri R, et al. Comparing IM residents with EM resident for their skills of ECG interpretation and outlining management plan accordingly. Journal of Medical Education 2007;11(1).

[8] Mahler SA, Wolcott CJ, Swoboda TK, et al. Techniques for teaching electrocardiogram interpretation: selfdirected learning is less effective than a workshop or lecture. Med Educ 2011;45(4):347-53. 